\title{
Los jardines infantiles y los ambientes activos modificantes
}

\author{
Silvia López de Maturana
}

Universidad de La Serena, Chile. Email: silvialml@gmail.com

\section{Carlos Calvo}

Universidad de La Serena, Chile. Email: carlosmcalvom@gmail.com

\begin{abstract}
Resumen: ${ }^{1}$ La propensión a aprender fluye en los párvulos, independiente del contexto; sin embargo, un ambiente activo modificante nutre y fortalece su tendencia a aprender; en cambio, se inhibe en un ambiente pasivo aceptante. Todos y todas permanentemente tienden a aprender lúdica y caóticamente, para lo cual observan con atención, sistematizan con rigor, experimentan con exigencia, comparando características, contrastándolas y poniéndolas a prueba, entre muchas otras operaciones. En un ambiente activo modificante la tarea del educador fluye de manera intencional, significativa y trascendente, ayudando a modificar estructural y cognitivamente a los estudiantes, mientras que en el ambiente pasivo aceptante, se subordina a los determinantes distales que no puede modificar, que le sirven de excusa por un trabajo que no favorece el aprendizaje activo y lúdico de cada uno y todos sus educandos.
\end{abstract}

Palabras clave: propensión a aprender, ambiente activo modificante, ambiente pasivo aceptante, mediación, modificabilidad cognitiva.

\section{Kindergartens and active modifying environments}

\begin{abstract}
The disposition to learn flows in preschool children, independently from the context; however, an active modifying environment nourishesand strengthens their tendency to learn; in contrast, it is inhibited in an accepting passive environment. They all and permanently tend to learn in a playful and chaotic way, for which they watch intently, rigorously systematize, experience demandingly, comparing features, contrasting and testing them, among many other operations. In an active modifying environment the educator's task flows in an intentional, meaningful and important way, helping modifying students structurally and cognitively, while in the passive accepting environment, it subordinates to distal determinants that cannot modify, which serves as an excuse for a work that does not promote an active and playful learning of each and all of its students.

Key words: propensity to learn, active modifying environment, accepting passive environment, mediation, cognitive modifiability.
\end{abstract}

\section{As creches e os ambientes ativos modificadores}

Resumo: A propensão para aprender flui nas crianças, independente do contexto; no entanto, um ambiente ativo modificador nutre e fortalece a sua tendência para aprender; entretanto, é inibida no ambiente passivo aceitante. Todos e todas permanentemente tendem a aprender divertida e caóticamente para o qual assistem 
atentamente, sistematizam com rigorosamente, experimentam com exigência, checando características, contrastando e testando-as, entre outras operações. Em um ambiente ativo modificador a tarefa do educador flui de maneira intencional, significativa e relevante, ajudando a modificar estrutural e cognitivamente aos estudantes, enquanto que no ambiente passivo receptor, está sujeita aos determinantes distais que não pode modificar e que servem de desculpa para um trabalho que não promove a aprendizagem ativa e lúdica de cada um e de todos os alunos.

Palavras-chave: propensão para aprender, ambiente ativo modificador, ambiente passivo aceitante, mediação, modificabilidade cognitiva.

\section{Ambientes de aprendizaje: activo modificante y pasivo aceptante}

El ambiente pasivo aceptante en el jardín infantil o en la escuela es provocado, promovido y reproducido por aquel profesorado ${ }^{2}$ que acepta resignadamente las dificultades de aprendizaje de los estudiantes, por lo que no innovan en sus estrategias ni provocan cambios significativos, en gran medida porque no los consideran necesarios. Una suerte de apatía pedagógica les lleva a mantener un ambiente homogéneo, controlado, sin sorpresas, donde cada estudiante seguirá aprendiendo del mismo modo que ya ha sido profetizado por sus profesores y aceptado por ellos mismos, esto es, que si es un estudiante con buenas calificaciones seguirá lográndolas y que si es uno con bajo rendimiento no logrará superar sus aprendizajes mediocres o sencillamente malos. El mismo se atribuirá la incapacidad para aprender, que reforzará con sus dificultades para sortear las complejidades del aprendizaje escolar.

Para evitarlo se necesita de un profesorado mediador que, a modo de determinante proximal, se interponga entre los estímulos y el educando para seleccionarlos, organizarlos, tamizarlos y para actualizar el potencial de desarrollo que cada estudiante lleva consigo. La intervención intencionada sobre los estímulos marca la diferencia entre un profesor común y un mediador, entre quien se preocupa de pasar contenidos y quien se ocupa en conocer las necesidades, características e intereses de sus estudiantes.

Buena parte del profesorado, posiblemente inquietos y curiosos al inicio de su carrera profesional, lentamente, aunque muchos de manera abrupta, fueron derivando hacia una postura pedagógica que supone que el estudiantado será tal cual lo percibió en las primeras clases, sino en los albores de la clase inicial, porque creen que sus capacidades son innatas e inmodificables por más esfuerzos que realicen. El dicho popular lo refrenda en expresiones como "nació así”, “es malo para las matemáticas”, “es tan bruto como su hermano", etc. Se autoconvencen de que la teoría que estudiaron no les sirve y que ellos hacen todo lo posible para que el estudiante aprenda, pero que no lo consigue porque no es capaz o porque es flojo. En este sentido, las salas de profesores de muchos establecimientos educacio- 
nales son mudos testigos de estas conversaciones pesimistas y desalentadoras. Esto es tan grave y frecuente que el Ministerio de Educación hace unos años creó el Programa de Mentores que destinaba a un profesor experimentando e inquieto para que acompañara, ayudara y estimulara al novel profesor, que recién ingresaba, a no desfallecer en sus sueños y mantener su espíritu pedagógico en alto ${ }^{3}$.

Es preciso distinguir entre el profesorado a aquellos que fácilmente claudican ante las dificultades de algún estudiante pensando que se trata de "una cuestión de raza, genes, herencia" (Feuerstein, 1988), por lo que están convencido de que no va a aprender por más esfuerzo que se haga, de aquellos convencidos de que puede aprender y hacerlo bien, por lo que buscan las mejores alternativas para lograrlo.

No se trata de generar falsas expectativas, sino de creer en la modificabilidad humana, que de acuerdo al mismo autor, aún en los casos en que hay un desorden genético, al educando le asiste la posibilidad de modificarse cognitivamente, simplemente porque los genes y cromosomas no son barreras inmodificables. Hay que cuidarse de confundir las particularidades de su condición con su índice de modificabilidad (López de Maturana, 2010). Uno alude a las características de manera más estática, el otro muestra el estado actual que puede ser modificado.

El ambiente activo modificante, al igual que el pasivo aceptante, es creado por el profesorado pero con una intencionalidad radicalmente diferente. El primero es acogedor de la diversidad y pleno de recursos que ayudan a la mediación intencional, significativa y trascendente que realizarán los docentes. Estos recursos no son sofisticados ni costosos, sino comunes y corrientes, pero que adquieren valor gracias a la intención mediadora del docente; en este ambiente florece la curiosidad, que mueve a indagar hipotetizando sobre como podrían ser los fenómenos y qué relaciones podría establecer entre ellos. El segundo, por el contrario, favorece el desinterés y la apatía respecto a la modificabilidad cognitiva y la propensión a aprender, lo que desincentiva los esfuerzos intencionales para que el otro aprenda y, paulatinamente el profesorado deja de sentirse responsable por el aprendizaje de sus educandos, arraigándose una suerte de fatalismo.

La propensión a aprender del alumno y la propensión a enseñar de los educadores encuentran terreno fértil donde fructificar sin mayores esfuerzos. Ambas propensiones, a aprender y a enseñar, son expresiones paradojales del mismo proceso. Quien aprende fluye en la enseñanza; quien enseña, aprende ${ }^{4}$. En este contexto de optimismo pedagógico resulta sencillo respetar al estudiante y sus peculiaridades, desarrollar su sentimiento de competencia y fomentar la conducta compartida. Las dificultades no se entienden como limitaciones sino como un estado de resistencia temporal que la mediación adecuada y pertinente podrá superar en breve tiempo; si la resistencia es mayor, obviamente, tomará más tiempo y dedicación.

Eso es análogo a la diferencia artificial que se hace entre el período 
crítico y el estado óptimo para el aprendizaje, dicotomizando en dos partes un proceso que debe ser considerado como complementario. El primero corresponde a los estadios evolutivos del ser humano para lo cual el educando debería cumplir ciertas condiciones para avanzar al siguiente. El segundo concierne a la maduración individual y da cuenta de la gran diversidad humana que existe, puesto que no todos aprendemos de la misma manera, al mismo ritmo y al mismo tiempo. Feuerstein propone el concepto de estados óptimos, que permite comprender las posibilidades de modificabilidad que tiene el ser humano, en contraposición a los períodos críticos, que encasillan el desarrollo afectando la autopercepción y la posibilidad de cambio estructural.

La creencia de que la inteligencia es fija y definitiva, tan arraigada en la sociedad y en algunos docentes, ha sido cuestionada definitivamente por la plasticidad cerebral, al mismo tiempo que nos impele a atender que la inteligencia que muestra un educando corresponde solo a una expresión temporal y momentánea de un estado que puede desarrollarse mucho más allá de lo que manifiesta. Aquí, germina la esperanza real y no ilusoria del educador que cree que la modificabilidad cognitiva es una opción genuina para ayudar a su estudiante con algún problema. Es diferente afirmar que algunos estudiantes no pueden aprender, a sostener que algunos de ellos están en un estado de resistencia a aprender.

En un ambiente activo modificante no se lucha para acallar la subjetividad de cada cual, pues no se confunde subjetividad con parcialidad, tal como se acostumbra en los ambientes pasivos aceptantes en que el juicio subjetivo es sinónimo de sesgo negativo y de seria dificultad para aprender. Esta distinción es crucial en el proceso educativo, actualmente dominado por pruebas objetivas en la suposición de que la objetividad evita injusticias. La subordinación a la cuantificación, que se desprende de una comprensión inadecuada del aporte de la ciencia dura, está dañando mucho a los educandos y educadores al subordinarlos a indicadores estandarizados y comunes para todos. No se trata de evitar indicadores, pero si de subordinarse a ellos, olvidando que no son más que criterios provisorios y cambiables cuando la experiencia enseña que son insuficientes.

Consideramos que educadores y educandos debemos dejar fluir nuestra subjetividad en los procesos de enseñanza y de aprendizaje, pero tenemos que cuidarnos de ser parciales e injustos. Esto es importante, pues con mucha frecuencia se confunde subjetividad con parcialidad e injusticia: "este profesor es muy subjetivo" para muchos equivale a decir "este profesor es muy injusto”. Consideramos que esta homologación es incorrecta y muy peligrosa, pues lleva al ostracismo escolar una característica humana insustituible. Por ejemplo, solo la intuición -qué más subjetivo que ella- nos permite tomar decisiones en situaciones de incertidumbre emergentes, donde la razón no logra arribar a una conclusión adecuada y pertinente. La eterna dicotomía entre razón e intuición debe ser superada por una concepción en la que cada una requiere de la otra, pues cada cual sirve propósitos diferentes, pero complementarios para el existir humano (Lehrer 2009). 
Cada estudiante y profesor es único e irrepetible gracias a su subjetividad, por lo que no debe inhibirse bajo ningún pretexto, sino desplegarse lúdica y rigurosamente, tal como el científico que busca y el artista que crea. Sin subjetividad no hay creación (Csikszentmihalyi 1998)

Las dificultades de aprendizaje y de socialización se asumen con optimismo en la esperanza de que si se trabaja metódica, afectuosa y rigurosamente, la modificabilidad estructural cognitiva será una realidad. La buena intención puede ser muy negativa porque induce a la impresión de que se ha hecho todo lo posible, por lo que el rótulo de incapaz parecerá que corresponde a una realidad definitiva. Esta es una de las razones por las que el mediador debe ser una persona idónea para que ayude metódica, sistemática y eficazmente a sus estudiantes a desarrollar sus funciones cognitivas, lo que les permitirá alcanzar niveles de mayor autonomía mental al comprender qué debe hacer, cómo hacerlo y para qué. En caso contrario, es altamente probable que el aprendizaje carezca de sentido, desmotive y se caiga en el círculo vicioso de la rutina, el desinterés y la desesperanza.

La modificabilidad cognitiva tiene una connotación más profunda que la de un simple cambio, porque es interna y altera el curso del desarrollo cognitivo del propio sujeto, sus habilidades, capacidades, rasgos de personalidad, competencias, etc., mientras que los cambios son externos, específicos y localizados, generalmente se limitan a alcanzar metas a corto plazo, de baja permanencia en el tiempo y débil resistencia a los impactos del medio (López de Maturana, 2010).

Es por esto que, el paso de un ambiente pasivo aceptante a uno activo modificante requiere de una decisión intencional y trascendente. Intencional porque se asume que es posible, probable y realizable. Para avanzar desde la mera posibilidad hacia su ejecución se requiere del compromiso personal y profesional de todos los involucrados, pues no se trata de un milagro sino del trabajo mancomunado de la comunidad educativa, ya que cada cual refuerza la curiosidad epistemológica y estimula la plasticidad cerebral del educando.

Blanca Nelly Gallardo (2102), colombiana y miembro de los grupos de Semilleros de Investigación, en conversación personal y comunicación escrita nos ha contado del caso de Carlos, que prueba fehacientemente que todo lo argumentado es posible. Carlos, que no aprendió a leer ni a escribir en los siete años de escuela, donde lo diagnosticaron con discapacidad cognitiva, no obstante lo cual, ha investigado a las mariposas en su hábitat natural, junto al colectivo de investigación "Semillero Sueños con Alas" integrado por 12 niños entre los 9 y 10 años, donde desarrollaban ejercicios investigativos, formativos y de exploración, que les ha permitido conocer y amar a la naturaleza. El grupo está liderado por la ambientalista Norita Londoño. A la fecha han identificado cinco ciclos básicos de vida de mariposas y más de 47 especies de plantas hospederas y nutricias, que permiten un avance significativo para la defensa de las mariposas en peligro de extinción. Actualmente cuenta con 18 años y ha montado su propio mariposario 
en la montañosa Verada El Portento, Municipio del Retiro, gracias a la cual vive satisfecho.

“...Carlos desarrolló una capacidad de observación asombrosa, aprendió a leer la naturaleza, a hacer 'lecturaleza' [lecto-naturaleza] y descubrió en las mariposas la posibilidad de abrirse al mundo y desarrollar muchas de sus potencialidades. Tengo la certeza de que el motor que logró esta transformación fue el amor: el haberse sentido reconocido y amado, logró que en el despertara el amor por la naturaleza y, en especial, por las mariposas” (Norita Londoño)

\section{Niños y niñas brillantes}

Los niños y niñas constantemente y sin esfuerzos crean ambientes activos modificantes. No pueden explicar cómo ni por qué lo hacen; tampoco son conscientes de sus bondades, simplemente encuentran en ello incentivo permanente para potenciar su propensión a aprender; sin proponérselo se vuelven mediadores entre ellos mismos; median en un contexto caótico y a un ritmo intenso y breve, brincando de una acción a otra. La mera insinuación de un orden externo, no emergente, tiende a coartar la natural propensión a aprender y a desviarlo de su ruta (Stiekel 2004).

Todo esto confunde al adulto que ha sido formado en la suposición de que los procesos de enseñanza y de aprendizaje fluyen lineal, secuencial y causalmente de uno a otro, en virtud de lo cual se inclina por sugerir, si no imponer, criterios normativos comunes para todos para ejecutar la tarea, los que fácilmente discriminan entre los estudiantes que han comprendido saben y los que no. Aunque el adulto no lo pretenda esta estrategia le conduce a discriminar y a segregar a sus estudiantes en función de la valoración que asigne a su rendimiento; por un lado, estarán los que son buenos para algo y, en el otro, aquellos que no lo son. Sin una estrategia que efectivamente ayude a superar estas marginaciones, las brechas se profundizarán cada vez más.

La convicción de tener alumnos buenos, regulares y malos se va enraizando en el ethos docente, lo que los lleva a perder el pudor de opinar negativamente de sus estudiantes delante de ellos mismos: "eso te pasa por llegar atrasado, no escuchaste” (F11 a LS CR AP 032)5, “no, acá no es que quieran o no, no mandan ustedes”, “a ver, yo estoy evaluando las disertaciones, no estoy na’ jugando” (F11 a LS CR AP 032), etc.

¿Qué comprenderá y cómo valorará un niño que es tratado de esta manera? Consideramos que paulatinamente estas opiniones dichas por su profesora, que es la autoridad a la que cree a pie juntillas, irán entretejiendo un entramado de auto exclusión y marginación educativa, que nutrirá la desesperanza del niño ante sus capacidades para aprender y pavimentará el camino del fracaso escolar. Si el profesor mediador tomara conciencia de lo sencillo que es crear un ambiente activo modificante fácilmente crearía ex- 
periencias de aprendizaje donde el contenido sería un buen medio para desarrollar operaciones mentales de alto nivel, tales como la identificación, comparación, análisis, síntesis, razonamiento hipotético, analógico, etc.

Podemos describir esta situación del siguiente modo: los pequeños fluyen en su propensión a aprender y el adulto los frena; puede hacerlo porque no sabe mediar y actúa de acuerdo al modelo de socialización que aprendió de pequeño, como cuando al preguntar en casa qué estaban comiendo, le respondían "come y calla” o porque el modelo paradigmático escolar es tan poderoso que, a pesar de haber estudiado que hay que escuchar el educando, se impone el modelo autocrático: es el profesor el que sabe, por lo que es él quien debe enseñar y el estudiante debe seguir las instrucciones. Este segundo caso es el más peligroso, puesto que al no mediar a sus educandos, los estímulos educativos en vez de ayudarles pueden obnubilar su conciencia y transformarlos en repetidores conductistas: estímulo / respuesta. Pareciera ser que el segundo caso es el que impera en la escuela con el consiguiente deterioro en las posibilidades de aprendizaje significativo de los estudiantes.

No exageramos al considerar que todos los niños, sin excepción étnica ni de clase social, incluidos aquellos con necesidades educativas especiales, son listos, despiertos, agudos, lúcidos, ingeniosos, avispados, perspicaces, geniales, sobresalientes, pues exploran con interés, observan meticulosamente, se involucran en cuerpo y alma, disfrutando con sus logros parciales que pronto ponen a prueba estableciendo nuevas relaciones que sorprenden por su complejidad y que no son fáciles de explicar a la luz de su corta edad e inexperiencia. Usan la lógica de manera tan correcta y rigurosa (Gopnik 2010) ${ }^{6}$ que asombran a los adultos por la precisión de sus inferencias, que son difíciles de rebatir por la contundencia argumental, aunque sean febles respecto a las complejidades del vivir social, sujetos a normas de convivencia que solo la experiencia les entregará. ¿̇Acaso no es esto el sueño de cualquier deportista (McCluggage 1977), artista (Nachmanovitch 2004), shamán (Amgaangaq 2001), matemático (Nowak, Martin A. \& Roger Highfield. 2012) y científico (Laszlo 2000)?

También nos animamos a señalar que los pequeños manifiestan una conducta mucho más comprensiva que los adultos, sesgados por sus experiencias e intereses; sin embargo, no aceptan una norma sin intentar ponerla a prueba. No buscan llevar la contraria, sino solo comprobar si es así como le dicen o si no lo es. Diríamos que solo es suficiente conversar con ellos y explicarles las razones por las que hay que tomar una decisión para que la acepten, aunque sea a regañadientes. Obviamente que hay momentos en los cuales es más probable que acepten lo que se les plantea y otros en los que es muy difícil que lo hagan, pues ellos, al igual que nosotros, viven intensos estados emocionales y deben aprender a calmarse cuando alguna situación les ha alterado y descentrado. No son ángeles; tampoco, demonios, sino niñas y niños creativos, curiosos y con la inteligencia necesaria y suficiente para sortear las dificultades que encuentran, pues por encima de todo propenden a aprender. Lamentablemente, no son indemnes 
al poder del adulto y muchos terminan sometiéndose a sus normas, reproduciéndolas y perdiendo su propensión creadora.

A lo largo de su crecimiento viven momentos de aprendizajes intensos, diversos y muchas veces paradojales o contradictorios entre sí, que deben aprender a resolver. Por ejemplo, viven momentos de conflictos éticos, como cuando el padre le enseña al hijo que no hay que mentir, pero que al recibir una llamada telefónica inoportuna, le pide u ordena que diga que no está. ¿Cómo resuelve esta situación una niña de cuatro o cinco años? No es fácil descifrar todas sus complejidades e implicaciones. La lógica le dice una cosa, pero la experiencia le enseña que no es suficiente concluir la deducción que infiere, pues el asunto es mucho más complejo. Las piezas no encajan, pues no basta adosarlas unas al lado de la otra, sino que hay que construirle un sentido, que es sinérgico y no sumativo. Es sinérgico porque el sentido no está en cada parte ni tampoco en la totalidad de ellas, sino en algo más, que es emergente, tal como el agua no está ni en el hidrógeno ni en el oxígeno, sino que emerge gracias a la complementariedad entre ambos.

Los pequeños van aprendiendo que la vida social se desenvuelve en diferentes planos, con obligaciones de diversas exigencias y fidelidades diferentes; esto lo pueden aprender de manera paulatina o sorpresiva e, incluso, de manera violenta. Según el contexto en el que crezca le podrá ser más fácil comprender que la vida no es coherente ni lógica sino que sigue un devenir caótico e incierto. De este aprendizaje dependerán en gran medida las decisiones que conformarán su curso vital.

Cualquier adulto que trate de explicar(se) la lógica interna que da coherencia a su cultura, se encontrará en serias dificultades si trata de argüir como se complementan. Si para el adulto es complejo por qué no podría serlo para un pequeño. Al igual que los adultos, el pequeño a lo largo de cada día debe sortear diferentes dificultades con mayor o menor éxito y consecuencias de diferente grado e importancia; a veces le irá bien, en otras, paladeará la frustración y el desencanto; sin embargo, si vive en un ambiente activo modificante tendrá más posibilidades de descubrir o inventar criterios que le ayudarán a tener más probabilidades de éxito que de fracaso: en cambio, si vive en un ambiente pasivo aceptante es altamente probable que llegue a ser una persona que padezca privación cultural.

La privación cultural consiste en la deplorable consecuencia de no haber contando con quien le proveyera de experiencias de aprendizaje mediado. Falta mediación cuando un adulto despoja al pequeño de la oportunidad de avanzar en el develamiento de un fenómeno que le llamó la atención. Evidentemente que una o pocas experiencias no mediadas no generan privación cultural, sino solo cuando se constituyen en un patrón reiterado y constante, del que el adulto puede no ser consciente de las nefastas consecuencias de su actuar, como cuando está presionado por cumplir con la programación escolar, con los horarios y las exigencias administrativas 
ciegas a la dinámica de los procesos educativos (Calvo, 2012). La privación cultural no está ligada a la pobreza como generalmente se cree, pero si está relacionada con la profecía autocumplida, que se nutre de la creencia de ser incapaz, todo lo cual refuerza el auto convencimiento sobre la propia ineptitud cognitiva. Esta presión puede ser muy burda o sutil, de tal modo que el educando casi no se da cuenta, pero poco a poco va haciéndose a imagen y semejanza de lo profetizado.

La educadora les dice que trabajarán en matemáticas, sumando las pelotitas de un collar en una imagen del libro. Les reparten los libros, buscan la página.

N1 encuentra la página; mirando el libro bosteza, tapa su cara con las manos, toma su estuche, saca todos los lápices, toma la figurita de plástico, se la muestra a su compañero del frente, la mueve y dice: “¡Toy en el barco!”.

... Mira la página de la tarea solicitada, comienza a contar con sus dedos, dibuja las pelotitas del collar en el dibujo de la señora. Luego mira la figura de plástico y nuevamente mira la página de la tarea, vuelve a mirar la figura de plástico y la marca en la hoja con su lápiz grafito. Vuelve a la hoja de la tarea, cuenta con sus dedos y dibuja las pelotitas del collar de la señora. Mira la hoja y cuenta nuevamente con sus dedos, pasa sus dedos por los ojos y luego dibuja las pelotitas del collar.

E1 se acerca a N1, le revisa su trabajo.

E1: “ ¡Ya tres, tres más uno, cuatro y cuatro más una, cinco, muy bien!" Le pone un ticket en sus respuestas correctas.

N1 sonríe y dice: “¡Este es mi trabajo!”

(Transcripción j_28_11 (1, 2, 3, 4); Extracto de VIDEO:j_28_11_3; TIEMPO: 24'19”)

Los pequeños se dedican a su tarea, al igual que la educadora; sin embargo, para los niños se trata de descubrir y establecer un patrón mientras están jugando y atentos a otros asuntos, es decir, parece que estuvieran distraídos, desatentos. Para la profesora, en cambio, se trata de comprobar si lo hecho está bien y no de mediar para que los educandos comprendan mejor y relacionen lo aprendido con lo que ellos y ellas desean. Ella verifica que la tarea se haya realizado de acuerdo a lo esperado, pero no los guía hacia nuevos descubrimientos. Ellas y ellos, sin embargo, lo hacen constantemente:

“¡Pan, y esta niñita se llama Paula!”, ...,

“¡La Pau ..., igual que la tía Ana Paula!”.

Sus intervenciones, intercaladas desordenadamente, buscan relacionar con lo que les viene a la cabeza y sin más pretensión. Es aquí, en este punto, donde consideramos que radica la fuerza educativa de estas interacciones y que fortalecen la propensión a aprender. La frontera entre un curso de acción y otro, entre la repetición y la mediación es sutil (Calvo, 2007). 
Recordamos cuando una sobrina pequeñita le pregunta a su madre a la hora de almuerzo: “¿qué hay debajo de la tierra?”; la madre le responde mediando la curiosidad de la niña al preguntarle qué es lo que ha visto donde unos obreros cavan para construir un edificio. "Piedras", responde, e inmediatamente vuelve a preguntar “qué hay debajo de esas piedras”. La mamá le replica “qué crees tú que habrá más abajo”. El diálogo mediado, sencillo y directo, sigue por un rato sin respuesta categórica, sino más bien indagatoria, señalando pistas para que la curiosidad de la niña se canalice hacia la definición de algún o algunos criterios de búsqueda, que le servirán para aclarar este caso en particular y para otros que sean parecidos. De este modo, la mediación es trascendente y no se limita solo a un caso particular, sino que permite elaborar patrones o pautas indagatorias.

Mientras escuchamos el diálogo, pensamos sobre que pasaría si continuaba mentalmente la tarea de los obreros y seguíamos cavando; ensoñábamos en ello cuando reparamos en algo paradojal: al inicio bajábamos y bajábamos, sin temor a caer, hasta llegar al centro de la tierra; luego, comenzábamos a subir con el peligro de resbalar y rodar hacia las profundidades. Una pregunta inocente -“¿qué hay debajo de la tierra?”-, sin mayor pretensión y que fácilmente se puede olvidar, tal como lo ha hecho la pequeña de la anécdota, nos lleva a encontrarnos sorpresivamente con una paradoja como aquellas dibujadas por Escher en sus escaleras o como si fuera un koan, planteando un problema absurdo y banal, como aquel propuesto por el maestro zen que palmotea y pregunta a sus discípulo: "Este el sonido de dos manos, ¿cuál es el sonido de una sola mano?"

Si bien quien educa puede mediar sin mayor esfuerzo, solo favoreciendo el curso de la inquietud infantil, lo común es que se constriña a comprobar si se hizo la tarea según lo programado, desperdiciando las frecuentes e infinitas posibilidades de mediar:

Alumna 1: “¡Membrillito!”

Alumna 2: “¡Mem- bri- llo tiene tres!” Cuenta con sus dedos las sílabas de la palabra membrillo.

Alumna 3 apuntando a Alumna 1: “ ¿Dijo membrillito!”

Alumna 1 cuenta con sus dedos las sílabas de membrillo; mira a Alumna 2 y le pregunta: “¿Cuántos tiene membrillo? ¡Sin contar con los dedos!"

Educadora 1: “¡Ya, terminó. El que quiera más leche ahí hay dos jarritos más!”

Alumna 2 se acomoda en la silla, pone sus manos debajo de la mesa, mira a Alumna 1.

Alumno 1 cuenta con sus dedos en silencio, mira a Alumna 1 y dice: “Tres!"

Alumna 1 mira a Alumna 2.

Alumna 2 muestra tres dedos.

Alumna 1 la mira y dice: “¡No!” Moviendo su cabeza en forma de negación.

Alumna 2 sube los codos a la mesa y apoya su cabeza en las manos, 
lleva sus ojos hacia arriba pensando.

Alumna 1: “¡No, pillería, porque no tenia que contar con los dedos, a ver tú Alumno 1!”

Alumno 1: “¡Tre!”

Alumna 1 cuenta con sus dedos las sílabas de la palabra membrillo que le preguntó a Alumna 2.

Educadora 1: “¡Tómense la leche rápido!”

Alumna 1 cuenta los dedos que levantó al decir cada sílaba, mira a Alumno 1 y le dice: “¡Uno, dos, tres, sí, bien!” Le sonríe.

Alumna 2 mira seriamente a Alumna 1.

(F11 b LS CS AP 042)

La educadora atenta a una de las tareas que tiene que realizar, en este caso, ocuparse de la nutrición de sus pupilos, desatiende la conversación infantil en la que las niñas y niños interactúan aprendiendo a descomponer una palabra, a lo largo de un proceso de auto exigencia que frecuentemente no es reconocido como tal, sino como una actividad sin importancia. El diálogo entre ellos es evaluativo del dominio que han logrado y de las connotaciones éticas de no engañar mientras se hace la tarea; también es intenso y demandante en el cumplimiento de las normas autoimpuestas: no decir membrillito ni contar con los dedos: "pillería, porque no tenia que contar con los dedos”.

Si esta situación fuera anecdótica no tendría mayor trascendencia; sin embargo, no lo es, ya que su ocurrencia es frecuente a lo largo de la jornada, con el "no" campeando en todo momento. Reconocemos lo difícil que resulta para la educadora atender a todos los niños y a las diferentes tareas que debe ejecutar; sin embargo, consideramos que solo bastaría dejar que sigan dialogando al mismo tiempo que les sugiere una pequeña variación para complejizar la descomposición silábica, por ejemplo, preguntándoles por el nombre de otra fruta y que la descompongan señalando cuál tiene más sílabas y letras, cuál les gusta más y que describan su sabor y aroma, etc. Eso ayudaría a desarrollar la metacognición puesto que los educandos tomarían conciencia de los procesos que utilizan para aprender, lo que conlleva consecuencias epistemológicas trascendentes para la educación escolar.

Es interesante notar que en esos momentos los pequeños están alegres y en permanente movimiento, a diferencia de lo que impone la cultura escolar donde se espera que permanezcan quietos, atentos y sin distraerse a lo que les dice la educadora y a las tareas que deben realizar, todo lo cual es imposible de lograr porque el niño y la niña son actividad pura. A medida que pasa el tiempo irán adaptándose y perdiendo la frescura de su indagación gratuita, que la hacen por el mero placer de aprender y que se complementa plenamente con el juego. Les encantan las emergencias, las incertidumbres y las improvisaciones.

A partir del juego los niños pueden transformar sin esfuerzo un ambiente pasivo aceptante en un activo modificante; gracias a él pueden co- 
existir temporalmente en uno y otro, cumpliendo las tareas que pide la educadora mientras siguen jugando a desafiarse informalmente. Aprenden polifacéticamente, esto es, más de un aprendizaje por vez, a diferencia de la escuela donde se supone que solo se puede aprender un solo asunto por vez.

Con ese tipo de práctica no es exagerado pensar que se generarán ambientes pasivos aceptantes, a pesar de que se declare que sus ambientes son activos modificantes porque están destinados exclusivamente a la enseñanza y al aprendizaje. Esto no pasa de ser una declaración bien intencionada, pero sin sustento empírico. De este modo, se continuará debilitando el índice de modificabilidad de los educandos, que aprenderán sin la ayuda de mediadores intencionales, significativos y trascendentes, y que no podrán desarrollar sus funciones cognitivas, lo que les impedirá acometer con éxito cualquier estudio que se propongan.

Ejemplos de ambientes activo modificantes y pasivo aceptantes:

\begin{tabular}{|c|c|}
\hline Ambientes activo modificantes & Ambientes pasivo aceptantes \\
\hline - Estudiantes beneficiados por la mediación. & - Riesgo de privación cultural \\
\hline - Creencia en la modificabilidad humana. & - Creencia en la inmodificabilidad humana. \\
\hline $\begin{array}{l}\text { - Ante la dificultad del hijo los padres le } \\
\text { guían y orientan. }\end{array}$ & $\begin{array}{l}\text { - Ante la dificultad del hijo los padres hacen } \\
\text { su tarea. }\end{array}$ \\
\hline $\begin{array}{l}\text { Un estudiante con problemas de lenguaje } \\
\text { asiste a una escuela comúnasistido por } \\
\text { especialistas. }\end{array}$ & $\begin{array}{l}\text { Un estudiante con problemas de lenguaje } \\
\text { asiste sólo a una escuela especial. }\end{array}$ \\
\hline $\begin{array}{l}\text { - Un niño con problemas cognitivos aprende } \\
\text { a transitar por las calles y a viajar en bus. }\end{array}$ & $\begin{array}{l}\text { - Un niño con problemas cognitivos no sale } \\
\text { solo porque sus padres son temerosos. }\end{array}$ \\
\hline $\begin{array}{l}\text { Profesorado preocupado por conocer la } \\
\text { historia y el estado de sus estudiantes ante } \\
\text { el aprendizaje. }\end{array}$ & $\begin{array}{l}\text { Profesorado que pone etiquetas y rótulos a } \\
\text { sus estudiantes de acuerdo a sus } \\
\text { dificultades. }\end{array}$ \\
\hline $\begin{array}{l}\text { Profesorado mediador intencional para } \\
\text { lograr la reciprocidad, significativo y } \\
\text { trascendente. }\end{array}$ & $\begin{array}{l}\text { Profesorado que transmite } \\
\text { unidireccionalmente contenidos sin } \\
\text { sentido para los educandos. }\end{array}$ \\
\hline $\begin{array}{l}\text { Profesorado mediador que busca lo nuevo } \\
\text { y lo complejo. }\end{array}$ & $\begin{array}{l}\text { Profesorado que repite constantemente los } \\
\text { mismos contenidos a todo tipo de } \\
\text { estudiantes. }\end{array}$ \\
\hline $\begin{array}{l}\text { Alternativas optimistas a pesar de las } \\
\text { dificultades de algunos estudiantes. }\end{array}$ & $\begin{array}{l}\text { Alternativas pesimistas dadas las } \\
\text { dificultades de algunos estudiantes. }\end{array}$ \\
\hline $\begin{array}{l}\text { Incorporación de nuevo vocabulario y } \\
\text { conceptos para desarrollar las habilidades } \\
\text { lingüísticas de los estudiantes. }\end{array}$ & $\begin{array}{l}\text { - No hay necesidad de incorporar nuevo } \\
\text { vocabulario ni conceptos. }\end{array}$ \\
\hline
\end{tabular}

\section{A modo de inferencia}

La efectividad de los aprendizajes infantiles debe hacernos reflexionar sobre nuestros procedimientos profesionales puesto que con muchísima frecuencia los adultos alteramos ese ambiente activo modificante, propiciador de aprendizajes sorprendentes, transformándolos en ambientes pasivo aceptantes, normado, sin atractivo y propiciador de relaciones 
preestablecidas. Por ejemplo, los objetivos establecidos en las Bases Curriculares de la Educación Parvularia en Chile no se consiguen, no por causa de los párvulos, sino por no saber apoyarse en su propensión a aprender. No debemos olvidar que un ambiente activo modificante estimula la plasticidad cerebral ya que la cantidad de sinapsis crece cuando el ambiente es más enriquecido.

La observación sistemática de dos años en los jardines infantiles, más las décadas de trabajo docente e investigador dedicado a la formación de profesores y educadoras de párvulos, nos muestra como muchos profesionales encargados de la educación formal desaprovechan las oportunidades de educar a sus educandos. Las excepciones a esta situación, que hemos investigado sistemáticamente a lo largo de varios años, nos muestran que esta situación es perfectamente superable (López de Maturana 2010). El problema radica en que los cambios que se desean no se conseguirán siguiendo las tendencias y orientaciones de las reformas educacionales en boga.

Los Ministerios de Educación deberían ocuparse en proponer reformas que simplifiquen el trabajo docente, al tiempo que permitan poner el acento en la propensión a aprender de los educandos. La simplificación no significa bajo ningún respecto superficializar el proceso, pues en la medida que el profesorado convierta en misterioso el tema que enseñará propiciará que los estudiantes comiencen a crear relaciones entre los conceptos y categorías, que el profesor encauzará sutilmente para que ellos profundicen en la complejidad que conlleva el tema en estudio.

Igualmente los Ministerios de Educación deberán cuidarse de caer en la tentación de que la enseñanza de la respuesta es lo medular, sino que deberían favorecer que los procesos de aprendizaje avancen de pregunta a pregunta, puesto que para avanzar requerirá respuesta, pero siempre relativas y nunca dogmáticas.

El proceso educativo debe recuperar su fuerza apoyándose en la propensión a aprender de cada educando, que se fortalece en el trabajo grupal de indagación genuina y no impuesta. 


\section{Notas}

${ }^{1}$ Artículo escrito gracias al proyecto de investigación FONDECYT 1110577: “Asombros educativos informales y propensión a aprender”. Las notas de campo corresponden a los registros etnográficos realizados por Carolina Rodríguez, profesora de Educación General Básica (2011) y Camila Segura, educadora de párvulos (2012).

${ }^{2}$ Reconocemos la legitimidad de diferenciar a los actores por su género; sin embargo, no nos parece que la distinción “el (la) alumno (alumna)” o cualquier otra modalidad, haga justicia a la demanda de la visibilidad impostergable, pues más bien se vuelve tediosa en la escritura y cansadora en la lectura. Para balancear esta situación en muchos casos usaremos la expresión femenina -la profesora- y no la neutra -el profesor- para referirnos a ambos. Finalmente, esperamos comprensión por este hecho a nuestras lectoras y lectores, pues bajo ninguna consideración implica ocultamiento ni menosprecio. Consideramos que debemos dedicarnos a crear una nueva manera de comunicarnos que haga justicia con elegancia lingüística, pues la propuesta del uso de la @ no lo fue ni tampoco arraigó, en parte porque en el habla no se puede usar.

${ }^{3}$ Nuestra experiencia de profesores formadores de profesores nos enseña que muchos nóveles profesores ilusionados con la tarea docente que inician pronto se convierten en profesores desilusionados de sus alumnos y de su profesión. Las capacitaciones posteriores no logran cambiar esa disposición.

${ }^{4}$ En el contexto del proyecto de investigación FONDECYT 1110577 la doctoranda Paulina Veas ha entregado su tesis doctoral sobre la propensión a enseñar.

${ }^{5}$ De este modo hemos codificados los registros etnográficos, lo que nos permite identificar proyecto, año, ciudad, etnógrafa, establecimiento.

${ }^{5}$ Según comunicación interna de nuestro co-investigador, Jorge Salgado, las principales características del razonamiento de los niños investigados son: "Modus Ponens ( $\mathrm{Si}$ P entonces Q. P. Por lo tanto Q) y Modus Tollens (Si P entonces Q. No Q. Por lo tanto, no P)”. 


\section{Bibliografía}

Amgaangaq (Christoph Quarch, compilador) (2001), Escucha la voz del hielo. La magia de la sabiduría ancestral de los Inuit. Urano. Barcelona.

Amgaangaq, Escucha la voz del hielo, <http://www.youtube.com/ watch?v=sxmniOktq-Y>

Calvo, Carlos (2013) (5ª edición), Del mapa escolar al territorio educativo: disoñando la escuela desde la educación. Universidad de La Serena. La Serena.

Calvo, Carlos (2007) “La sutileza como germen educacional copernicano”. En: Educación de Adultos (Alemania) 2007:69.

Csikszentmihalyi, Mihaly (1998), Creatividad: el fluir y la psicología del descubrimiento y la invención. Paidos. Barcelona.

Feuerstein, Reuven et al. (1988), Don't accept me as I am: helping retarded performers to excel. Plenum. New York.

Gallardo Cerón, Blanca Nelly (2012), “Más allá de los sentidos: una experiencia de la condición de lectura directa a las páginas de la naturaleza”. Comunicación personal, La Serena, 26 Abril

Gopnik, Alison (2000), El filósofo entre pañales. Relaciones sorprendentes sobre la mente de los niños y cómo se enfrentan a la vida. Planeta. Madrid.

Laszlo, Ervin (ed.) (2000), La revolución de la conciencia. Un diálogo multidisciplinario. Dos días con Stanislav Grof, Erwin Laszlo y Peter Russell. (Prólogo de Ken Wilber; Epílogo de Yehudi Menuhin). Editorial Kairós. Barcelona (disponible en Internet).

Lehrer, Jonah (2009), How we decide. Mariner Books. New York.

López de Maturana, Silvia (2010) (2ª ed.), Los buenos profesores: educadores comprometidos con un proyecto educativo. Universidad de La Serena. La Serena.

Ídem (2010), Maestros en el Territorio. Universidad de La Serena. La Serena.

Mc Cluggage, Denise (1977), El esquiador centrado. Editorial Cuatro Vientos. Santiago.

Nachmanovitch, Stephen (2004), Free Play: la improvisación en la vida y en el arte. Paidós. Barcelona.

Nowak, Martin A. \& Roger Highfield (2012), Super cooperadores. Las 
Polis, Revista Latinoamericana, Volumen 13, $N^{\circ} 37,2014$

matemáticas de las evolución, el altruismo y el comportamiento humano (o por qué nos necesitamos los unos a los otros para triunfar), Ediciones B. Barcelona.

Stiekel, Bettina (2001), 2004. Los niños preguntan, los Premios Nobel contestan. Ediciones ONIRO S.A. Barcelona.

Recibido: 03.06.2013

Aceptado: 30.01.2014 